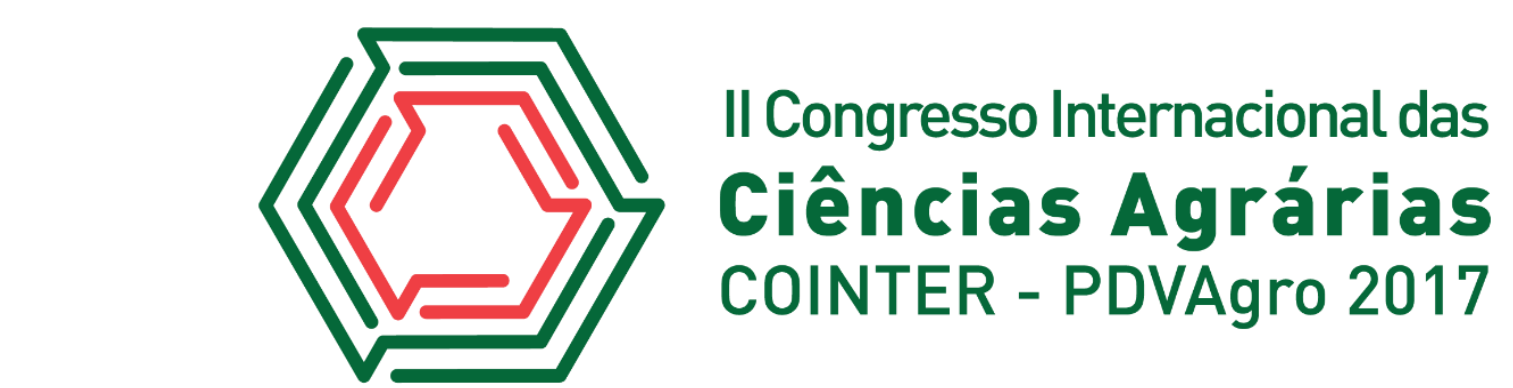

\title{
COMBINAÇÕES DE DIFERENTES FONTES DE ADUBOS ORGÂNICOS NO CULTIVO DA BETERRABA EM COLORADO DO OESTE RONDÔNIA
}

\author{
Apresentação: Pôster
}

\begin{abstract}
Darllan Junior Luiz Santos Ferreira de Oliveira ${ }^{1}$; Dayane Barbosa Pereira ${ }^{2}$; Bruno Emanuel Lemes do Nascimento ${ }^{3}$; Luiz Cobiniano de Melo Filho ${ }^{4}$
\end{abstract}

\section{Introdução}

A beterraba (Beta vulgaris L.) é uma das principais hortaliças cultivadas no Brasil, com evidências de sua origem segundo Vasconcelos (2009), nas regiões européias e norte africanas de clima temperado.

A produção no Brasil se encontra principalmente na região centro-sul. Cerca de $42 \%$ das propriedades produtoras de beterraba estão na Região Sudeste e 35\% na Região Sul (CAMARGO FILHO; MAZZEI, 2002). O cultivo orgânico de hortaliças tem mostrado desenvolvimento significante nos últimos anos no Brasil. À procura por alimentos saudáveis, gerados em sistemas ecologicamente sustentáveis, tem se tornado cada vez mais realidade no país, do ponto de vista do comprador e também por causa da dificuldade dos agricultores familiares arcarem com os custos elevados dos sistemas agrícolas convencionais (MARTINS, 2008).

No Brasil adubação química e mais comumente utilizada e apresenta resultados evidentes na produtividade da cultura da beterraba. Porém, a adubação orgânica realizada com estercos de origem animal, resíduos vegetais e agroindustriais é uma alternativa para a redução de custos de produção com fertilizantes minerais. Eles melhoram as qualidades químicas e biológicas do solo (SILVA et al., 2001), aumentam a população de microorganismo no solo.

A resposta à aplicação da adubação química e orgânica na cultura da beterraba depende do

\footnotetext{
${ }^{1}$ Engenharia Agronômica, Instituto Federal de Educação Ciência e Tecnologia de Rondônia, darllan.junior@outlook.com

2 Engenharia Agronômica, Instituto Federal de Educação Ciência e Tecnologia de Rondônia, dayane_barbosa13@hotmail.com

${ }^{3}$ Técnico em Agropecuária, Instituto Federal de Educação Ciência e Tecnologia de Rondônia, b.nascimento7456@gmail.com

${ }^{4}$ Mestre, Instituto Federal de Educação Ciência e Tecnologia de Rondônia, luiz.cobiniano@ifro.edu.br
} 
tipo de solo, da temperatura, da época e maneira de adubação; fonte, tipo e forma de aplicação do adubo. A falta de informações agronômicas sobre a avaliação de diferentes variedades e tipos de fórmulas e doses de adubação limitam sua expansão de cultivo. Desta maneira é de suma importância encontrar métodos adequados de adubação para o seu cultivo nas diferentes regiões do país, sendo necessária a realização de pesquisas que avaliem os tipos e doses de adubações em diferentes regiões do país.

Desde modo o presente trabalho teve como testar diferentes fertilizantes na produção de beterraba no município de Colorado do Oeste, Rondônia, buscando uma alternativa na produção desta olerícola de grande importância.

\section{Fundamentação Teórica}

A beterraba é uma cultura bastante exigente em termos nutricionais, requerendo um programa de adubação equilibrado capaz de repor os nutrientes extraídos pela cultura, evitando assim o esgotamento do solo. Porém, adubações excessivas contendo N podem afetar na qualidade da raiz, provocando o acúmulo de glutamina (SOUZA et al., 2003).

A matéria orgânica no solo é considerada uma das principais fontes de energia e nutrientes ao sistema, capaz de manter a produtividade dos solos. Entre outros benefícios da matéria orgânica, destaca-se a melhoria das condições físicas do solo, o fornecimento de energia para o crescimento microbiano (SILVA e RESCK, 1997). As fontes de matéria orgânica como o esterco e biofertilizante são menos agressivas ao ambiente e possibilitam o desenvolvimento de uma agricultura menos dependente de produtos industrializados, bem como a viabilidade da propriedade por muitos anos (DELEITO et al., 2000).

Apesar de se encontrar na literatura trabalhos que avaliaram o efeito da adubação nitrogenada na beterraba em condições de solos brasileiros, pouco se sabe sobre o efeito de doses de diferentes fonte e tipos de adubos no cultivo desta hortaliça para as condições edafoclimáticas do estado de Rondônia.

\section{Metodologia}

O experimento foi realizado no Instituto Federal de Educação, Ciência e Tecnologia de Rondônia, campus Colorado do Oeste, localizado na BR 435, Km 63, localizado no Cone Sul do Estado de Rondônia.

O solo é classificado como ARGISSOLO VERMELHO Eutrófico (EMBRAPA, 2006). O 
clima predominante da região é tropical úmido com estação seca bem definida entre junho e agosto, tipo Awi pela classificação de Köppen, com temperatura média em torno de $28^{\circ} \mathrm{C}$, máximas de $40^{\circ} \mathrm{C}$ e mínimas de $16^{\circ} \mathrm{C}$ e precipitações médias anuais de aproximadamente $2.100 \mathrm{~mm}$ (TREVISAN et al., 2011).

As mudas de beterraba foram produzidas em bandejas de isopor de 288 cédulas e irrigadas diariamente por meio de microaspersão, no viveiro de mudas existentes no campus, de $08 \mathrm{~h} 00 \mathrm{~min}$ as 17h00min, com tempo de funcionamento de 10 minutos a cada 2 horas, pressão de funcionamento de 20 mca e vazão média de 14,82 L hora-1 e transplantadas 21 dias após semeadura em canteiros com dimensão de 2,20 x 1,20, no espaçamento de 25 X $10 \mathrm{~cm}$ (TIVELLI et al., 2011).

No campo o experimento foi irrigado através o sistema de irrigação por aspersão convencional, com turno de rega de aplicação correspondente de dois dias. Foram utilizados seis tratamentos: T1 - Testemunha adubação básica T2 - Biofertilizante, T3 - fertipeixe, T4 Composto Orgânico + fertipeixe, T5 - Composto Orgânico + Biofertilizante e T6 - Composto Orgânico + Biofertilizante + Fertpeixe. Aplicação do fertipeixe e do biofertilizante foram aplicados a cada semana na proporção de $3 \%$.

A área total de cada canteiro foi de 2,64 m², contendo oito fileiras espaçadas de $25 \times 10$ $\mathrm{cm}$. Foram consideradas como bordadura as duas fileiras externas de cada canteiro, além dos $10 \mathrm{~cm}$ das extremidades de cada fileira. Foi realizada adubação química de fundação em todos os canteiros, de acordo com análise do solo.

Tabela 1: Atributos químicos do solo da área experimental. Fonte: Própria

\begin{tabular}{cccccccccc}
\hline $\mathrm{pH}$ & $\mathrm{Al}^{+3}$ & $\mathrm{H}^{+}$ & $\mathrm{Ca}^{+2}$ & $\mathrm{Mg}^{+2}$ & $\mathrm{~K}^{+}$ & $\mathrm{SB}$ & $\mathrm{CTC}$ & $\mathrm{P}$ & $\mathrm{MO}$ \\
\hline $\begin{array}{c}\mathrm{H}_{2} \mathrm{O} \\
5,4\end{array}$ & 0,19 & 5,81 & 3,08 & $\begin{array}{c}\mathrm{cmol}_{\mathrm{c}} \mathrm{dm}^{-3} \\
4,54\end{array}$ & 0,16 & 14,6 & 18 & 9,6 & 35 \\
\hline
\end{tabular}

O biofertilizante foi preparado de acordo com a metodologia descrita por Vairo dos Santos (1992) em biodigestor hermético, de fermentação anaeróbica, utilizando 50\% esterco bovino fresco e $50 \%$ de água, mais $0,5 \%$ de calcário dolomítico, $1 \%$ de cálcio marinho e $250 \mathrm{~g}$ de ácido bórico. Aplicação foi realizada 60 dias após a fermentação.

O preparo do composto orgânico foi efetuado a partir da utilização de diferentes resíduos de origem vegetal, capins e folhas secas, sobre os quais serão adicionados $0,5 \%$ de calcário dolomítico 
com base no volume total dos resíduos utilizados. A testemunha foi composta pela adubação mineral de fundação recomenda para a cultura.

O delineamento experimental utilizado foi blocos ao acaso, com 06 tratamentos e quatro repetições, totalizando 24 parcelas.

A colheita foi realizada 90 dias após a germinação, para determinação da produção $\left(\mathrm{kg} / \mathrm{m}^{2}\right)$, e diâmetros. Os dados foram submetidos à análise de variância e as médias comparadas pelo teste de Tukey, a 5\% de probabilidade utilizando-se o software SISVAR (FERREIRA, 2000).

\section{Resultados e Discussões}

Para o parâmetro produtividade, não houve diferença estatisticamente entre os tratamentos analisados. $\mathrm{O}$ tratamento composto orgânico mais biofertilizante foi o que apresentou maior rendimento, quando comparado à testemunha, apresentando um incremento de $12 . \%$ na produtividade. Esse resultados se assemelha ao trabalho realizado por Costa et al. (2006), trabalhando com a cultura do rabanete utilizando varias fontes de orgânicos. (Tabela 2).

Para o variável diâmetro longitudinal (DL), houve diferença estatisticamente entre tratamentos testados. O fertipeixe proporcionou o maior DL $(89,95 \mathrm{~mm})$. Para o diâmetro transversal (DT), não houve diferença significativa entre os tratamentos, todavia o fertipeixe apresentou o maior diâmetro (Tabela 2).

Tabela 2: Médias da analise de Tukey para as variáveis: medidas de diâmetro transversal (DT), diâmetro longitudinal (DL), produtividade de massa fresca (PROD), na cultura da beterraba cultivada no município de Colorado do Oeste. Fonte: Própria

\begin{tabular}{cccc}
\hline TRATAMENTOS & DT $(\mathrm{mm})$ & DL $(\mathrm{mm})$ & PROD (t/ha) \\
\hline Testemunha & $60,37 \mathrm{a}$ & $74,13 \mathrm{~b}$ & $22,08 \mathrm{a}$ \\
Biofertilizante & $64,44 \mathrm{a}$ & $76,32 \mathrm{~b}$ & $25,56 \mathrm{a}$ \\
Fertipeixe & $68,98 \mathrm{a}$ & $89,95 \mathrm{a}$ & $23,36 \mathrm{a}$ \\
Compostagem+ Fertipeixe & $68,33 \mathrm{a}$ & $83,96 \mathrm{ab}$ & $25,21 \mathrm{a}$ \\
Compostagem+ Biofertilizante & $66,28 \mathrm{a}$ & $81,84 \mathrm{ab}$ & $26,23 \mathrm{a}$ \\
Compostagem+Biofertilizante+Fertipeixe & $68,61 \mathrm{a}$ & $81,71 \mathrm{ab}$ & $24,19 \mathrm{a}$ \\
Media & 66,17 & 81,32 & 24,43 \\
CV\% & 16,03 & 8,14 & 15,39 \\
\hline
\end{tabular}

\section{Conclusões}

Nas condições em que o trabalho foi desenvolvido, em solo de boa fertilidade, a maior 
produtividade da beterraba foi obtida com a utilização do composto orgânico mais biofertilizante.

Há não significância quanto ao parâmetro produtividade pode esta relacionado ao levado nível de matéria orgânica existe no solo.

\section{Referências}

ALVES AU; PRADO RM; GONDIM ARO; FONSECA IM; CECÍLIO FILHO AB. 2008. Desenvolvimento e estado nutricional da beterraba em função da omissão de nutrientes. Horticultura Brasileira 26: 292-295.

CAMARGO FILHO, W.P.; MAZZEI, A.R. Mercado de beterraba em São Paulo. Informações Econômicas, São Paulo, v.32, n.4, p.54-56, 2002.

COSTA CC; OLIVEIRA CD; SILVA CJ; TIMOSSI PC; LEITE IC. 2006. Crescimento, produtividade e qualidade de raízes de rabanete cultivadas sob diferentes fontes e doses de adubos orgânicos. Horticultura Brasileira, 24: 118-122.

DELEITO, C.S.R. ; CARMO, G.F. do; ABBOUND, A.C. de S; FERNANDES, M. do C. de A. Sucessão Microbiana Durante o Processo de Fabricação do Biofertilizante Agrobio. In: FERTIBIO 2000, Santa Maria, RS. Anais... Santa Maria, RS: Sociedade Brasileira de Ciências do Solo e da Sociedade Brasileira de Microbiologia. CD - ROM.

FERREIRA, D.F. Sistema de análise estatística para dados balanceados (SISVAR). Lavras: UFLA - DEX, 2000.

LASKE, P. Abonamiento de las hortalizas. Hannover: Verlagsgesellschaft für Ackerbau mbH., 1962. $51 \mathrm{p}$.

MARTINS, G. de O. Desenvolvimento de raizes de cenoura (Daucus carota L. var Esplanada) em solos submetidos a diferentes compostos orgânicos. Rio Largo, 2008. 43 f. Dissertação (Mestrado em Agronomia) Programa de Pós-graduação em Agronomia, Universidade Federal de Alagoas.

SILVA, E. C.; MIRANDA, J. R. P.; ALVARENGA, M. A. R. Concentração de nutrientes e produção do tomateiro podado e adensado em função do uso de fósforo, de gesso e de fontes de nitrogênio. Horticultura Brasileira, v. 19, n. 1, p. 64-69, 2001.

SOUZA, R.J. de.; FONTANETTI, A.; FIORINI, C.V.A.; ALMEIDA, K. de. Cultura da beterraba (Cultivo convencional e Cultivo orgânico). Lavras, 2003, 37p.

TIVELLI, S.W.; FACTOR, T.L.; TERAMOTO, J.R.S.; FABRI, E.G.; MORAES, A.R.A.; TRANI, P.E. \& MAY, A. Beterraba: Do plantio à comercialização. Boletim técnico IAC. Campinas, n.210, 2011.

TREVISAN, G. V.; BISPO, P. C.; MAIA, A. L. S. Análise de diferentes técnicas declassificação digital no mapeamento do uso e cobertura da terra. Disponível em: <http://mtcm19.sid.inpe.br/col/sid.inpe.br/mtcm19\%4080/2009/12.03.18.40/doc/Trevi

san_etal_2008_Geonordeste.pdf>. Acesso em: 05 de agosto de 2011.

VAIRO DOS SANTOS, A. C. Biofertilizante líquido: o defensivo agrícola da natureza. 2 ed. rev. Niterói: EMATER-RJ, 1992. 16 p. (Agropecuária Fluminense, 8).

VASCONCELOS, G.B. Adubação orgânica e biodinâmica na produção de Chicória (Cichorium endivia) e beterraba (Beta vulgaris), em sucessão. Botucatu, 2009. 85f. Dissertação (Mestrado em Agronomia) Programa de Pós-graduação em Agronomia, Universidade Estadual Paulista.

EMPRESA BRASILEIRA DE PESQUISA AGROPECUÁRIA - EMBRAPA. Centro Nacional de Pesquisa de Solos. Sistema brasileiro de classificação de solos. 2 ed. Rio de Janeiro, 2006. 206p. 